\title{
Solutions to Improve the Thermal Protection of the Administrative Building
}

\author{
Valeriya Kostenko ${ }^{1,}$, , Nailya Gafiyatullina ${ }^{1}$, Gafur Zulkarneev ${ }^{1}$, Aleksandr Gorshkov ${ }^{1}$, \\ Marina Petrichenko ${ }^{1}$ and Sara Movafagh ${ }^{2}$ \\ ${ }^{1}$ Peter the Great St. Petersburg Polytechnic University, 195251 Politechnicheskaya str. 29, St. \\ Petersburg, Russia \\ ${ }^{2}$ University of Guilan, 4199613776 Khalij Fars highway, Ghazvin road, Rasht, Iran
}

\begin{abstract}
At the end of the $90 \mathrm{~s}$, with the introduction of changes in the regulatory documents of the Russian Federation №3 to SNiP II-3-79*, regulatory requirements for thermal protection of buildings were revised towards increase. For this reason, the buildings built till 2000 don't conform to modern requirements. The actual solution of this problem is to carry out works on renovation of facades of the existing buildings with the use of innovative materials. As object of research one of educational cases of Peter the Great St. Petersburg Polytechnic University has been chosen, where by practical consideration the size of the actual thermal resistance of external walls has been determined by heat flux meter, the numerical value of which was significantly lower than the standard values. Based on the obtained data two modern ways of thermal insulation of facades (Ventilated Façade System (VFS) and External Thermal Insulation Composite System (ETICS)) have been analyzed, the assessment of energy saving potential and the discounted payback period of the investments directed to warming of facades has been made.
\end{abstract}

\section{Introduction}

About $95 \%$ of the buildings of the total amount existing housing stock in Russia do not correspond to modern requirements for thermal insulation, i.e. they are obsolete. The physical state of the building facades is also often faulty. In this regard, measures for heat insulation of external building envelope should be recognized as reasonable.

In addition to improving the appearance of buildings, raise thermal insulation of the building envelope leads to decrease of transmission heat losses [1-6]. The lower the heat loss in the building, the lower the amount of thermal energy is required to bring to the building from a heat supply source to compensate for transmission losses. Thus, the thermal insulation leads to decrease energy consumption in the building and consequently to reduction of payments for heating [3-6].

One of the important characteristics of thermal insulation performance of the building envelope is the resistance to heat transfer. The methods of determining it based on

\footnotetext{
* Corresponding author: kostenkolera@gmail.com
} 
laboratory tests of material samples or fragments of building structures in climatic chambers, or researches are conducted directly in a natural external environment.

The latter method is more suitable because it does not require destruction of the structure and enables to determine the characteristics of the actual design and not the model. The test allows to quantify the thermotechnical characteristics of the building envelope (heat transfer resistance, thermal conductivity, thermal flux density) and to check their compliance with the regulatory requirements established in accordance with the rules [10], to determine the real heat loss through exterior walls.

The aim of the article is a quantitative analysis of the thermotechnical characteristics of the building envelope, which are carried out by comparing the actual heat transfer resistance values with normative data, offer methods of the building envelope insulation with their technical and economic comparison, a choice of the most effective technical solutions.

\section{Initial design data}

The building was designed in 1970 that is the reduced value of the heat transfer resistance of the building envelope $R_{0}^{r}$ was determined according to the standard [7] by climatic parameters of Leningrad and was equal $0.98 \mathrm{~m}^{2} \cdot{ }^{\circ} \mathrm{C} / \mathrm{W}$.

\section{The results of field observations}

Experimental research of exterior walls R-value of Peter the Great St. Petersburg Polytechnic University Gidrokorpus-2 (Fig. 1) was carried out using ITP-MG4.03/5(I) "POTOK" heat flux density meter. The test was conducted from 15 to 20 January 2016. During this period, an outdoor air temperature varied in the range from minus $23{ }^{\circ} \mathrm{C}$ to minus $2{ }^{\circ} \mathrm{C}$, an inner wall surface temperature - from $14{ }^{\circ} \mathrm{C}$ to $16{ }^{\circ} \mathrm{C}$. The building walls are made of solid brick $510 \mathrm{~mm}$ thick with ceramic plating.

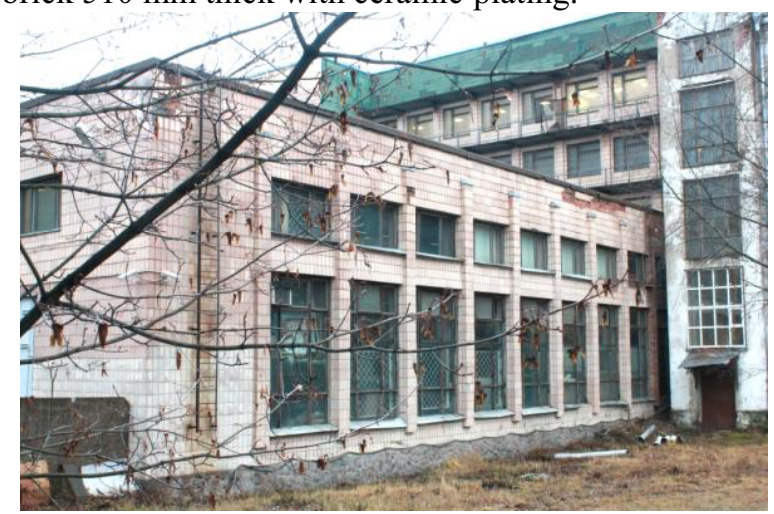

Fig. 1. Peter the Great St. Petersburg Polytechnic University Gidrokorpus-2.

Fig. 2 is a graph showing changes in heat fluxes throughout the entire study period. The actual heat transfer resistance has been calculated in the area of heat fluxes stationary thermal conditions ranging from $30.6 \mathrm{~W} / \mathrm{m}^{2}$ to $33.95 \mathrm{~W} / \mathrm{m}^{2}$. Further, the test was discontinued, since a sharp warming began from 19 January 2016, the outside air temperature became higher than minus $10^{\circ} \mathrm{C}$. 
1,2

1

0,8

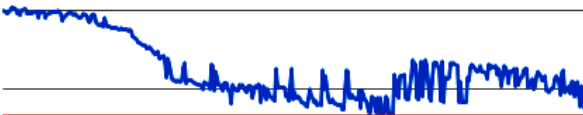

0,6

0,4

0,2

0

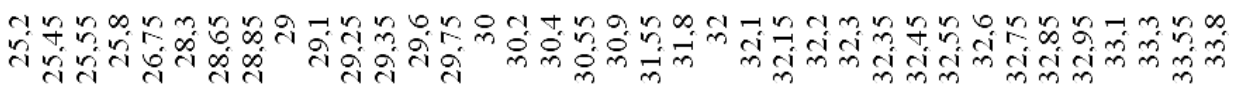
$-\mathrm{RT}, \mathrm{m}^{\wedge} 2 \cdot{ }^{\circ} \mathrm{C} / \mathrm{W} \longrightarrow \mathrm{Rk}, \mathrm{m}^{\wedge} 2 \cdot{ }^{\circ} \mathrm{C} / \mathrm{W}$

Fig. 2. Graph of heat flux changes.

Fig. 3 is a graph of temperature changes on the wall surfaces indoors $\left(\tau_{1}\right)$ and outdoors $\left(\tau_{2}\right)$.
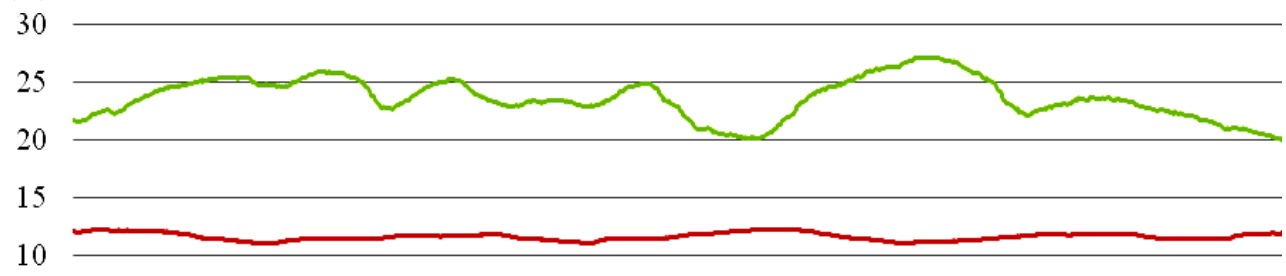

5

0

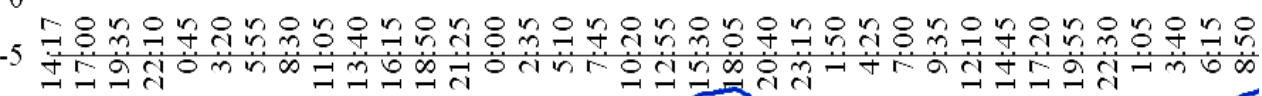

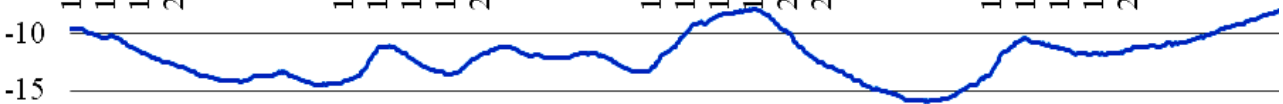

$-20$

$$
-\tau 1-\tau 2-\tau 1-\tau 2
$$

Fig. 3. Graph of temperature changes: $\tau_{1}$ - the inner wall surface temperature, $\tau_{2}-$ the outer wall surface temperature, $\tau_{1}-\tau_{2}-$ temperature difference.

In according with the standard [9] the building envelope $\mathrm{R}$-value $R_{k}$ is defined as the difference between the average temperatures of the building envelope inner and outer surfaces during the test period to the average heat flux density passing through the enclosure. According to what it is equal to $0.73 \mathrm{~m}^{2} \cdot{ }^{\circ} \mathrm{C} / \mathrm{W}$. Thermal resistance calculated by taking into account additional factors, equal to $0.89 \mathrm{~m}^{2} \cdot{ }^{\circ} \mathrm{C} / \mathrm{W}$.

For the purpose of comparison of the thermal conductivity actual values of the materials used in construction, with project values, masonry U-value was determined: $\lambda_{k}=0.7$ $\mathrm{W} / \mathrm{m} \cdot{ }^{\circ} \mathrm{C}$. 


\section{Current regulatory requirements}

According to the requirements $[10,12]$ in St. Petersburg the basic value of the reduced total thermal resistance of the building envelope is $R_{0}^{r}=2,5 \mathrm{~m}^{2} \cdot{ }^{\circ} \mathrm{C} / \mathrm{W}$, the normalized value of the reduced total thermal resistance of the building envelope is $R_{0}^{n o r m}=1,57 \mathrm{~m}^{2} \cdot{ }^{\circ} \mathrm{C} / \mathrm{W}$.

\section{Comparative analysis of the façade solutions}

Compare the walls R-values when warming by ETICS (External Thermal Insulation Composite System) $-R_{\text {ETICS, }}$ and VFS (Ventilated Façade System) $-R_{V F S}$. (Fig. 4)

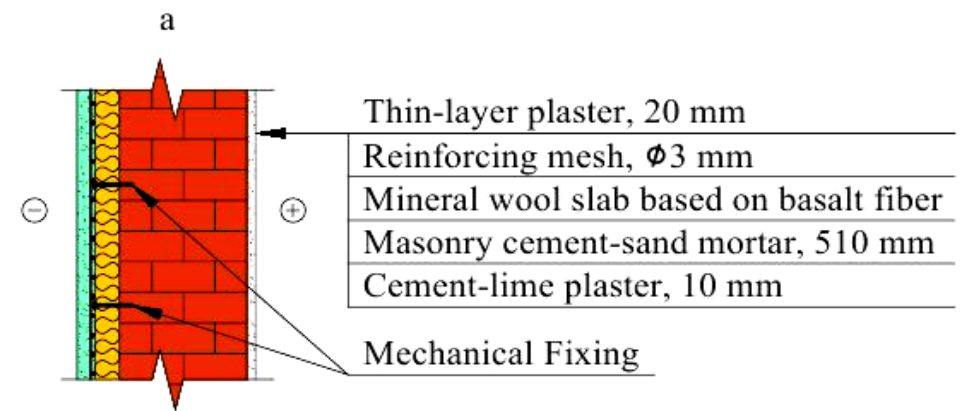

$\mathrm{b}$

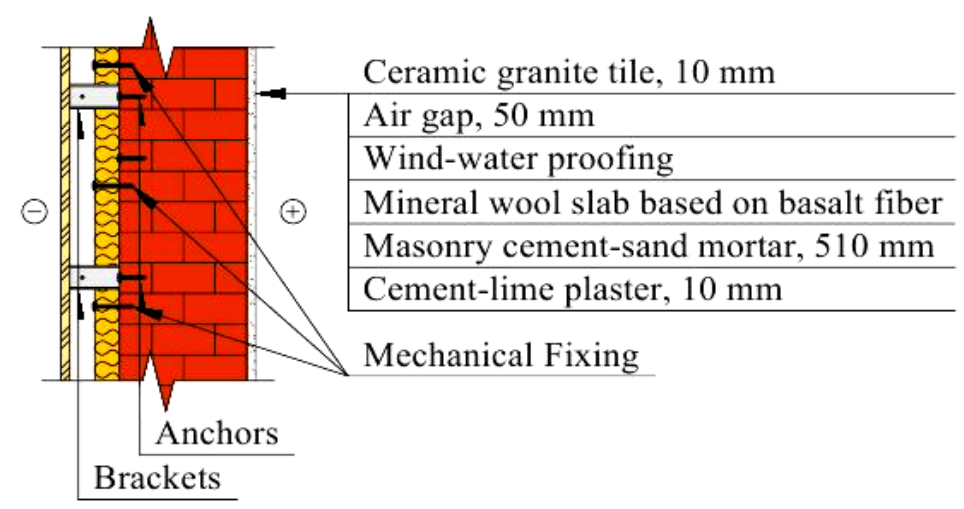

Fig. 4. Schematic representation of the considered external wall construction: a - with mineral wool thermal insulation with plaster finish; $b$ - with a ventilated suspended facade system.

Temperature analyze of the wall with mineral wool thermal insulation based on basalt fiber ( $\rho=100 \mathrm{~kg} / \mathrm{m}^{3}$ semirigid) with thin layer plaster finish (Fig. 4a) [13]:

1 - cement-lime plaster: $\lambda_{1}=0.87 \mathrm{~W} / \mathrm{m}^{\circ}{ }^{\circ} \mathrm{C}, \delta_{1}=0.01 \mathrm{~m}$;

2 - brick masonry: $\lambda_{2}=0.7 \mathrm{~W} / \mathrm{m} \cdot{ }^{\circ} \mathrm{C}, \delta_{2}=0.51 \mathrm{~m}$;

3 - mineral wool slab: $\lambda_{3}=0.045 \mathrm{~W} / \mathrm{m} \cdot{ }^{\circ} \mathrm{C}, \delta_{3}=0.1 \mathrm{~m}$;

4 - protective layer from thin layer plaster: $\lambda_{4}=0.87 \mathrm{~W} / \mathrm{m} \cdot{ }^{\circ} \mathrm{C}, \delta_{4}=0.045 \mathrm{~m}$.

Rated thermal resistance was determined according to the standard [13], taking into account the structural features of the facade systems.

The ETICS R-value is equal to $R_{\text {ETICS }}=2.7 \mathrm{~m}^{2} \cdot{ }^{\circ} \mathrm{C} / \mathrm{W}>1.57 \mathrm{~m}^{2} \cdot{ }^{\circ} \mathrm{C} / \mathrm{W}$. 
Temperature analyze of the wall with suspended facade system with ventilated air-space and with mineral wool thermal insulation based on basalt $\left(\rho=100 \mathrm{~kg} / \mathrm{m}^{3}\right.$ semirigid) (Fig. $4 b)$ :

1 - cement-lime plaster: $\lambda_{l}=0.87 \mathrm{~W} / \mathrm{m} \cdot{ }^{\circ} \mathrm{C}, \delta_{l}=0.01 \mathrm{~m}$;

2 - brick masonry: $\lambda_{2}=0.7 \mathrm{~W} / \mathrm{m} \cdot{ }^{\circ} \mathrm{C}, \delta_{2}=0.51 \mathrm{~m}$;

3 - mineral wool slab: $\lambda_{3}=0.045 \mathrm{~W} / \mathrm{m} \cdot{ }^{\circ} \mathrm{C}, \delta_{3}=0.1 \mathrm{~m}$;

4 - air gap: $R_{\text {a.g. }}=0$, because air-space is not closed;

5 - ceramic granite tile (heat-insulating quality of decorative screen is not taken into account).

The VFS R-value is equal to $R_{V F S}=2.06 \mathrm{~m}^{2} \cdot{ }^{\circ} \mathrm{C} / \mathrm{W}>1.57 \mathrm{~m}^{2} \cdot{ }^{\circ} \mathrm{C} / \mathrm{W}$.

\section{Determination of transmission heat losses}

The calculation of transmission heat losses during the heating period $Q_{b e}$ is performed by the overall heat transfer equation. The value of heat loss during the heating period:

- actual: $Q_{b e}=548.5 \mathrm{Gcal} /$ year;

- ETICS: $Q_{\text {be ETICS }}=180.8 \mathrm{Gcal} /$ year;

- VFS: $Q_{b e V F S}=237 \mathrm{Gcal} /$ year.

Thus, the heat energy savings will be:

$-\Delta Q_{\text {ETICS }}=367.7 \mathrm{Gcal} /$ year after ETICS application,

$-\Delta Q_{V F S}=311.5 \mathrm{Gcal} /$ year after VFS application.

Methods of calculating capital costs for additional insulation, operating costs before and after thermal insulation, as well as the payback period of energy-saving measures are described in detail in the works [15-19].

Calculate the economic effect in relation to the two selected variants of facades heat insulation:

$-\Delta E_{\text {ETICS }}=520663.2 \mathrm{rub} /$ year;

$-\Delta E_{V F S}=441084 \mathrm{rub} /$ year.

Capital expenditure on insulation of external walls of the existing building:

$-\Delta C_{\text {ETICS }}=14742323.8 \mathrm{rub}$.

$-\Delta C_{V F S}=40983113.0 \mathrm{rub}$.

Simple payback period of insulation the outer wall of the existing building insulation with a thickness of $100 \mathrm{~mm}$ is:

$-T_{\text {ETICS }}=28.3$ years;

$-T_{V F S}=92.9$ years.

Note that the calculated payback period was obtained without taking into account:

- tariffs raising for thermal energy;

- interest on the loan (in the case of the application of loan funds to carry out events for the insulation of building external walls);

- discounting of achieved future cash flows as a result of implementation of energysaving measures under consideration and of reduce the heat energy loss for heating.

For this reason, the calculated values of the projected payback period of the investment can be regarded only as estimates.

Heat tariffs increase annually. This means that the annual cost savings will increase with each subsequent year (heating period).

Taking into account the above-mentioned factors, the projected payback period of investment in additional facades insulation is determined by a logarithmic equation [15-20]. According to the equation the payback period of energy-saving measures was calculated taking into account the total capital expenditure for its implementation, the rising cost of tariffs for thermal energy $(r)$, discounting future cash flows $(i)$, achieved by cost-cutting as a result of the implementation of energy-saving measures. 
Values $r$ and $i$ are fickle and change every year. Possible options for payback, depending on the changes of the variables are presented in Table 1 for ETICS and in Table 2 for VFS.

Table 1. Correlation analysis results of the payback period of ETICS taking into account the changes in the average annual rate of the rising cost of tariffs for thermal energy $(r)$ and in the future cash flows discount factor on the key rate of the Central Bank of the Russian Federation ( $i$.

\begin{tabular}{|c|c|c|c|c|c|c|c|c|c|c|c|c|}
\hline$i$ & 0.05 & 0.06 & 0.07 & 0.08 & 0.09 & 0.1 & 0.11 & 0.12 & 0.13 & 0.14 & 0.15 & 0.16 \\
\hline 0.05 & - & 24.70 & 22.46 & 20.70 & 19.27 & 18.08 & 17.08 & 16.21 & 15.45 & 14.79 & 14.20 & 13.67 \\
\hline 0.06 & - & - & 24.72 & 22.49 & 20.74 & 19.32 & 18.13 & 17.13 & 16.26 & 15.51 & 14.84 & 14.25 \\
\hline 0.07 & - & - & - & 24.75 & 22.53 & 20.78 & 19.37 & 18.18 & 17.18 & 16.32 & 15.56 & 14.90 \\
\hline 0.08 & - & - & - & - & 24.77 & 22.57 & 20.83 & 19.41 & 18.23 & 17.23 & 16.37 & 15.61 \\
\hline 0.09 & - & - & - & - & - & 24.80 & 22.60 & 20.87 & 19.46 & 18.28 & 17.28 & 16.42 \\
\hline 0.1 & - & - & - & - & - & - & 24.82 & 22.64 & 20.91 & 19.51 & 18.33 & 17.33 \\
\hline 0.11 & - & - & - & - & - & - & - & 24.84 & 22.67 & 20.96 & 19.55 & 18.65 \\
\hline 0.12 & - & - & - & - & - & - & - & - & 24.86 & 22.71 & 21.00 & 19.60 \\
\hline 0.13 & - & - & - & - & - & - & - & - & - & 24.88 & 22.74 & 21.04 \\
\hline 0.14 & - & - & - & - & - & - & - & - & - & - & 24.91 & 22.77 \\
\hline 0.15 & - & - & - & - & - & - & - & - & - & - & - & 24.93 \\
\hline 0.16 & - & - & - & - & - & - & - & - & - & - & - & - \\
\hline
\end{tabular}

Table 2. Correlation analysis results of the payback period of VFS taking into account the changes in the average annual rate of the rising cost of tariffs for thermal energy $(r)$ and in the future cash flows discount factor on the key rate of the Central Bank of the Russian Federation ( $i$ ).

\begin{tabular}{|c|c|c|c|c|c|c|c|c|c|c|c|c|}
\hline$i$ & 0.05 & 0.06 & 0.07 & 0.08 & 0.09 & 0.1 & 0.11 & 0.12 & 0.13 & 0.14 & 0.15 & 0.16 \\
\hline 0.05 & - & 63.84 & 51.91 & 44.41 & 39.17 & 35.26 & 32.21 & 29.75 & 27.71 & 26.00 & 24.53 & 23.26 \\
\hline 0.06 & - & - & 63.99 & 52.08 & 44.59 & 39.34 & 35.42 & 32.36 & 29.90 & 27.85 & 26.13 & 24.66 \\
\hline 0.07 & - & - & - & 64.13 & 52.25 & 44.76 & 39.51 & 35.59 & 32.52 & 30.04 & 27.99 & 26.27 \\
\hline 0.08 & - & - & - & - & 64.28 & 52.42 & 44.93 & 39.68 & 35.75 & 32.67 & 30.19 & 28.13 \\
\hline 0.09 & - & - & - & - & - & 64.42 & 52.59 & 45.10 & 39.84 & 35.90 & 32.82 & 30.33 \\
\hline 0.1 & - & - & - & - & - & - & 64.56 & 52.76 & 45.27 & 40.01 & 36.06 & 32.97 \\
\hline 0.11 & - & - & - & - & - & - & - & 64.70 & 52.92 & 45.44 & 40.17 & 37.35 \\
\hline 0.12 & - & - & - & - & - & - & - & - & 64.83 & 53.09 & 45.61 & 40.33 \\
\hline 0.13 & - & - & - & - & - & - & - & - & - & 64.97 & 53.25 & 45.77 \\
\hline 0.14 & - & - & - & - & - & - & - & - & - & - & 65.10 & 53.41 \\
\hline 0.15 & - & - & - & - & - & - & - & - & - & - & - & 65.24 \\
\hline 0.16 & - & - & - & - & - & - & - & - & - & - & - & - \\
\hline
\end{tabular}

To solve the problem of estimating the projected payback period of investment in energy efficiency magnitude $r$ was adopted of the average over the last 5 years $(16 \%)$, and the value i was for 2016 (11\%).

In this case the payback period of investment will be: 
$-T_{\text {ETICS }}=18.7$ years;

$-T_{V F S}=37.4$ years.

On results of calculations in Tables 1 and 2, it can be assessed how the investment payback period varies depending on the differentiation of the coefficient the average annual tariff raising for thermal energy $(r)$ and the discount rate of future cash flows on the key rate of the Central Bank of the Russian Federation ( $i$ ). It can also be concluded that the facade renovation of obsolete buildings is possible, if $r \geq i$, and is not justified, when $r<i$.

\section{Results}

According to the experience results:

- thermotechnical characteristics and envelopes of the building were evaluated with regulatory requirements [10]. Required design heat transfer resistance is $R_{0}^{r}=2,5 \mathrm{~m}^{2} \cdot{ }^{\circ} \mathrm{C} / \mathrm{W}$, actual heat transfer resistance is $R_{0}=0.89 \mathrm{~m}^{2} \cdot{ }^{\circ} \mathrm{C} / \mathrm{W}$;

- options for renovation of facades are considered in the most widespread ways. Heat transfer resistance values of facade systems were founded: $R_{0 \text { ETICS }}=2.7 \mathrm{~m}^{2} \cdot{ }^{\circ} \mathrm{C} / \mathrm{W}$ at ETICS, $R_{0 V F S}=2.06 \mathrm{~m}^{2} \cdot{ }^{\circ} \mathrm{C} / \mathrm{W}$ at VFS;

- transmission heat losses for heating were defined: actual $Q_{b e}=548.5 \mathrm{Gcal} /$ year; with ETICS $Q_{\text {be ETICS }}=180.8 \mathrm{Gcal} /$ year; with VFS $Q_{b e}$ VFS $=237 \mathrm{Gcal} /$ year;

- capital costs for performance of work upon insulation of administrative building facades and investment payback period for both insulation methods, taking into account the average annual tariff raising for thermal energy and discounting future cash flows on the key rate of the Central Bank of the Russian Federation were calculated: these are $\Delta C=14$ $742323,80 \mathrm{rub}, T_{\text {ETICS }}=18.7$ years at ETICS; these are $\Delta C=40983113,0 \mathrm{rub}, T_{V F S}=37.4$ years at VFS.

\section{Conclusion}

By results of experience it was revealed that the actual condition of external walls of the academic building of Peter the Great St. Petersburg Polytechnic University does not meet current regulatory requirements for thermal protection. In order to eliminate the revealed discrepancy it is necessary to carry out additional work on the building envelopes renovation by one of the proposed methods of warming: ETICS or VFS. The least expensive method is SFTK, which is characterized by lower estimated payback period of investments. Its application can reduce the heat losses through the walls by about $57 \%$

Implementation of the aforementioned recommendation will allow to bring closer the building into compliance with modern requirements for thermal protection, which will increase the building energy performance class.

\section{References}

1. V.I. Livchak, AVOK, 3, 62-67 (2010)

2. V.I. Livchak, AVOK, 6, 14-21 (2012)

3. N.I. Vatin, D.V. Nemova, P.P. Rymkevich, A.S. Gorshkov, Mag. of Civ. Eng, 8, 4-14, (2012)

4. A.S. Gorshkov, D.V. Nemova, P.P. Rymkevich, Roof. and Ins. Mat., 2, 34-39 (2013)

5. A.S. Gorshkov, D.V. Nemova, P.P. Rymkevich, Energ. Sav., 2, 26-32 (2014)

6. N.I. Vatin, D.V. Nemova, A.S. Gorshkov, Build. Mat., Eq., Tech. of XXI cen., 1, 3639 (2013)

7. SNiP II-A.7-62* Therm. Eng. Des. Reg. 
8. SNiP II-A.6-62 Build. Clim. and Geoph.

9. GOST R 54853-2011 Build. and. Cons.

10. SP 50.13330.2012 Therm. Prot. of Build.

11. SP 131.13330.2012 Build. Clim.

12. GOST 30494-2011 Res. and Pub. Build.

13. GOST R 53786-2010 Therm. Ins. Com. Fac. Sys.

14. GOST R 54851-2011 Cons. Build. Env. Het.

15. D.V. Nemova, N.I. Vatin, A.S. Gorshkov, A.V. Kashabin, P.P. Rymkevich, D.N. Tceitin, Cons. of Un. Build. and Str., 8, 93-115 (2014)

16. L. Svatovskaya, A. Sychova, M. Sychov, V. Okrepilov, MATEC Web of Conferences, 53, Article Number 01023 (2016)

17. A.S. Gorshkov, N.I. Vatin, P.P. Rymkevich, AVOK, 3, 32-36 (2014)

18. A.A. Romanova, P.P. Rymkevich, A.S. Gorshkov, Tech. and Tech. Ser. Pr., 4, 68-74 (2014)

19. A.S. Gorshkov, MSUCE, 12, 136-146 (2015)

20. A.S. Gorshkov, V.I. Livchak, Building envelope: review and analysis of the regulatory requirements (Lap Lambert Academing publishing, Saarbruecken, 2015) 